\title{
Penerapan Nilai-nilai Keislaman dan Keindonesiaan Sekolah Indonesia Den Haag (SIDH) Belanda sebagai Pilar Pendidikan Karakter Islam
}

\author{
Khobli Arofad ${ }^{1}$, Nadjma Laynufaria Almas ${ }^{2}$, Ahmad Mushofihin ${ }^{3}$, \\ Veny Widiyanti Putri ${ }^{4}$ \\ 1,2,3,4 Institut Agama Islam Negeri Kudus \\ ${ }^{1}$ khobliarofad@gmail.com, ${ }^{2}$ almasnadjma@gmail.com, ${ }^{3}$ mushof.07@gmail.com, \\ ${ }^{4}$ venywidiyantiputri021@gmail.com
}

\begin{abstract}
This study aims to describe how the application of Islamic and Indonesian values in the Hague Indonesian School (SIDH) as a pillar of Islamic character education. The method used in this research is to use qualitative approach, using descriptive type. The results showed that the application of Islamic and Indonesian values in the Hague Indonesian School (SIDH) was applied through learning activities, not only that, but also through other activities in the institution. These values can run of course with the help of educators or schools who are very enthusiastic in strengthening Islamic character education, especially in the Netherlands and Europe. With the Islamic and Indonesian values, it can make the character attached to the students in The Hague Indonesian School (SIDH).
\end{abstract}

Key Word: Indonesian Values, Islamic Character Education, Islamic Values

\begin{abstract}
Abstrak
Penelitian ini bertujuan untuk menguraikan tentang bagaimana penerapan nilainilai keislaman dan keindonesiaan di Sekolah Indonesia Den Haag (SIDH) sebagai pilar pendidikan karakter Islam. Metode yang digunakan pada penelitian ini adalah menggunakan pendekatan kualitatif, dengan menggunakan jenis deksriptif. Hasil penelitian menunjukkan bahwa penerapan nilai-nilai keislaman dan keindonesiaan di Sekolah Indonesia Den Haag (SIDH) diterapkan melalui kegiatan pembelajaran, tidak hanya itu, tetapi juga melalui kegiatan-kegiatan lainnya yang ada pada lembaga pendidikan tersebut. Nilai-nilai tersebut dapat berjalan tentunya dengan bantuan pendidik atau pihak sekolah yang sangat antusias dalam penguatan pendidikan karakter Islam khususnya di negara Belanda dan Eropa. Dengan adanya nilai-nilai keislaman dan keindonesiaan tersebut dapat menjadikan karakter tersebut melekat pada diri peserta didik di Sekolah Indonesia Den Haag (SIDH).
\end{abstract}

Kata Kunci: Nilai Keindonesiaan, Nilai Keislaman, Pendidikan Karakter Islam

\section{Pendahuluan}

Pendidikan khususnya pendidikan

Islam mempunyai fungsi dalam pembentukan transformasi pengetahuan (aspek kognitif), nilai moral atau norma (sikap afektif), dan mengendalikan perilaku (aspek Jurnal Intelektual: Jurnal Pendidikan dan Studi Keislaman Volume 10, Nomor 3, Desember 2020 
Penerapan Nilai-nilai Keislaman dan Keindonesiaan Sekolah Indonesia Den Haag (SIDH) Sebagai Pilar Pendidikan

Karakter

Oleh: Khobli Arofad, Nadjma Laynufaria Almas, Ahmad Mushofihin, Veny Widiyanti Putri

pendidikan agama dapat menjadikan peserta didik berkarakter mulia. Adanya pendidikan agama Islam dapat menghasilkan peserta didik yang mempunyai nilai-nilai keimanan, ketakwaan, berakhlak mulia, yang mencakup budi pekerti, moral, dan etika sebagai salah satu perwujudan pendidikan karakter Islam.

Belanda merupakan salah satu negara berpenduduk mayoritas non muslim dan sangat berbeda jauh dengan bangsa Indonesia, baik dari sikap, perilaku, dan kebudayaannya. Dalam pembentukan karakter harus memiliki lingkungan yang mendukung. Perilaku manusia $83 \%$ diakibatkan oleh apa yang dilihatnya, $11 \%$ oleh apa yang didengar, dan $6 \%$ sisanya dari kombinasi stimulus. ${ }^{1}$ Misalnya pengaruh teman-teman dan gurunya dalam membentuk karakter peserta didik.

Dengan adanya lingkungan yang kondusif anak-anak akan merasa nyaman dan aman. Sekolah Indonesia Den Haag (SIDH) sangat memperhatikan pembentukan karakter peserta didik baik melalui kegiatan intrakurikuler maupun ekstrakurikuler. Maka dari itu, dalam pembentukan karakter peserta didik, sekolah-sekolah Indonesia yang berada di luar negeri khususnya Sekolah Indonesia Den Haag (SIDH) mampu menunjang dalam menginternalisasikan nilai-nilai keislaman dan keindonesiaan bagi anak-anak Indonesia yang bersekolah di sana.

Untuk menerapkan, mengamalkan, menanamkan, mempelajari, mengajarkan, atau memahami nilai-nilai keislaman dan keindonesiaan, tentunya dibutuhkan pengalaman, pembelajaran, dan pemahaman yang mendalam mengenai nilai-nilai keislaman dan keindonesiaan tersebut. Dalam pendidikan agama Islam, pengembangan nilai-nilai keislaman merupakan hal yang substansial karena dalam pendidikan agama Islam diajarkan mengenai pengamalan nilainilai keislaman dan keindonesiaan dalam kehidupan sehari-hari.

Adapun tantangan yang dihadapi dalam pendidikan khususnya pendidikan agama Islam yaitu bagaimana menginternalisasikan nilai-nilai keislaman dan keindonesiaan kepada peserta didik/siswa secara utuh. Tidak sekedar terikat pada ilmu pengetahuan saja (aspek kognitif), namun meliputi aspek sikap (afektif) dan perilaku (psikomotor) agar peserta didik memiliki kualitas keimanan, ketakwaan dan akhlak yang mulia. Sebagaimana dalam UndangUndang Republik Indonesia Nomor 20 Tahun 2003 tentang Sistem Pendidikan Nasional Bab II pasal 3 menjelaskan bahwa: "Pendidikan nasional berfungsi mengembangkan

\footnotetext{
${ }^{1}$ Musda Mulia dan Ira D. Aini, Karakter Manusia Generasi Muda (Bandung: Nuansa Cendekia, 2013), Indonesia: Butir-butir Pendidikan Karakter untuk 87. 
Penerapan Nilai-nilai Keislaman dan Keindonesiaan Sekolah Indonesia Den Haag (SIDH) Sebagai Pilar Pendidikan

Karakter

Oleh: Khobli Arofad, Nadjma Laynufaria Almas, Ahmad Mushofihin, Veny Widiyanti Putri

kemampuan dan membentuk watak serta mengimplementasikan agar dapat membina peradaban bangsa yang bermartabat dalam mencerdaskan kehidupan bangsa, bertujuan untuk berkembangnya potensi peserta didik agar menjadi manusia yang beriman dan bertakwa kepada Tuhan Yang Maha Esa, berakhlak mulia, sehat, berilmu, cakap, kreatif, mandiri dan menjadi warga negara yang demokratis serta bertanggung jawab."

Dalam tujuan pendidikan nasional yang telah disebutkan, sekolah tidak hanya sekedar melekat dalam bidang akademik yang menitikberatkan pada pemahaman akademik atau ilmu pengetahuan saja, melainkan hal ini harus diselaraskan dengan adanya pembentukan karakter pada peserta didik. Keselarasan antara pendidikan akademik dan pembentukan karakter hal ini perlu dikaitkan khususnya pada lembaga pendidikan baik di sekolah dan di rumah, apabila dilakukan secara seimbang dapat menjadi pijakan dalam membentuk atau menghasilkan peserta didik menjadi manusia yang berintelektual dari aspek keimanan, akhlak, dan ilmu pengetahuan.

Penerapan nilai-nilai keislaman dan keindonesiaan sebagai pilar pendidikan karakter Islam dapat mengakomodasi peserta didik dalam mengamalkan,

karakter peserta didik menjadi manusia yang mampu memahami nilai tersebut dalam kehidupan sehari-harinya, sehingga segala pengaruh negatif dan perubahan zaman dapat diatasi oleh peserta didik dengan baik.

Penelitian terdahulu yang berkaitan dengan penerapan nilai-nilai keislaman dan keindonesiaan sebagai pilar pendidikan karakter. Penelitian yang dilakukan oleh Asril Aziz Situmorang tahun 2012 yang berjudul "Komunikasi Keluarga dalam Penerapan Nilai-Nilai Keislaman di Kelurahan Simatorkis Sisoma Kecamatan Angkola Barat”. Dalam penelitian ini, memiliki kesamaan dengan yang penulis teliti, yaitu sama-sama membahas penerapan nilai-nilai keislaman. Adapun perbedaan penelitian yang dilakukan oleh Asri Aziz Situmorang memfokuskan pada lingkup keluarga yang berada di Kelurahan Simatorkis Sisoma Kecamatan Angkola Barat, sedangkan penulis lebih memfokuskan pada lembaga pendidikan formal di Sekolah Indonesia Den Haag (SIDH).

Hasil penelitian oleh Asri Aziz Situmorang menjelaskan bahwa komunikasi keluarga sangat dibutuhkan dalam menerapkan atau mengimplementasikan nilai-

$\begin{array}{ll}2 \text { "UU No. } 20 \text { Tahun } 2003 \text { Tentang Sistem Pendidikan } & \text { http://simkeu.kemdikbud.go.id/index.php/peraturan1/8 } \\ \text { Nasional," Simkeu Kemendikbud, diakses } 11 \text { Januari } & \text {-uu-undang-undang/12-uu-no-20-tahun-2003-tentang- }\end{array}$ 2021, sistem-pendidikan-nasional. 
Penerapan Nilai-nilai Keislaman dan Keindonesiaan Sekolah Indonesia Den Haag (SIDH) Sebagai Pilar Pendidikan

Karakter

Oleh: Khobli Arofad, Nadjma Laynufaria Almas, Ahmad Mushofihin, Veny Widiyanti Putri

nilai keislaman (akidah, ibadah, dan akhlak) sehingga anak nantinya akan dapat memahami dan mengamalkan nilai-nilai keislaman tersebut. Tentunya dalam menerapkan nilai-nilai keislaman tersebut didukung dengan adanya pengajian majelis taklim, yasinan dan kesadaran para orang tua sendiri. ${ }^{3}$

Selanjutnya, penelitian yang dilakukan oleh Erwin Putera Permana, Frans Aditya Wiguna, dan Novita Dewi Rosalia tahun 2019 yang berjudul "Pengembangan Permainan Berlandaskan Nilai Karakter Keindonesiaan pada Siswa Sekolah Dasar". Penelitian ini sama yang penulis teliti yaitu membahas mengenai nilai-nilai karakter keindonesiaan. Adapun perbedaan pada penelitian Erwin Putera Permana, Frans Aditya Wiguna, dan Novita Dewi Rosalia lebih mengerucut tentang pengembangan permainan dan hanya sebatas peserta didik pada Sekolah Dasar (SD). Sedangkan penelitian yang kami teliti penerapan nilainilai keindonesiaan secara umum. Dalam penelitian tersebut bahwa nilai-nilai karakter keindonesiaan merupakan prioritas dalam pendidikan dasar. Dengan adanya permainan

\footnotetext{
${ }^{3}$ Asril Azis Situmorang, "Komunikasi keluarga dalam penerapan nilai-nilai keislaman di Kelurahan Simatorkis Sisoma Kecamatan Angkola Barat" (undergraduate, IAIN Padangsidimpuan, 2012), http://etd.iain-padangsidimpuan.ac.id/5678/.

${ }^{4}$ Erwin Putera Permana, Frans Aditia Wiguna, dan Novita Dewi Rosalia, "Pengembangan Permainan Berlandaskan Nilai Karakter Keindonesiaan pada

Siswa Sekolah Dasar," PINUS: Jurnal Penelitian Inovasi Pembelajaran 5, no. 1 (12 November 2019): 99-107, https://doi.org/10.29407/pn.v5i1.13857.

5 Toni Ardi Rafsanjani dan Muhammad Abdur Razaq, "Internalisasi Nilai-Nilai Keislaman Terhadap Perkembangan Anak Di Sekolah Dasar Muhammadiyah Kriyan Jepara," Profetika: Jurnal
}

secara otomatis siswa dapat meningkatkan semangat dan antusiasme siswa dalam mengaplikasikan dan memahami karakter keindonesiaan di sekolah dasar. ${ }^{4}$

Selanjutnya, penelitian yang dilakukan oleh Toni Ardi Rafsanjani dan Muhammad Abdur Rozaq tahun 2018 yang berjudul "Internalisasi Nilai-Nilai Keislaman Terhadap Perkembangan Anak di Sekolah Dasar Muhammadiyah Kriyan Jepara". Penelitian ini terdapat kesamaan dengan yang kami teliti, yaitu tentang implementasi atau penerapan nilai-nilai keislaman. Adapun perbedaannya, penelitian yang dilakukan oleh Toni Ardi Rafsanjani dan Muhammad Abdur Rozaq lebih memfokuskan pada peserta didik sekolah dasar, sedangkan penelitian yang kami teliti lebih memfokuskan pada pembentukan karakter islami bagi anak-anak Indonesia yang berada di luar negeri yaitu Belanda. Hasil penelitian menunjukkan bahwa implementasi nilai-nilai keislaman di SD Muhammadiyah Kriyan Jepara mampu dalam membina para peserta didik menjadi pelajar yang maju, melalui nilai-nilai pendidikan agama Islam yang sering dilakukan dalam kehidupannya sehari-hari. ${ }^{5}$ 
Penerapan Nilai-nilai Keislaman dan Keindonesiaan Sekolah Indonesia Den Haag (SIDH) Sebagai Pilar Pendidikan

Karakter

Oleh: Khobli Arofad, Nadjma Laynufaria Almas, Ahmad Mushofihin, Veny Widiyanti Putri

Oleh karena itu, pada tulisan ini penulis akan membahas bagaimana penerapan nilai-nilai keislaman dan keindonesiaan di Sekolah Indonesia Den Haag (SIDH) terhadap peserta yang berada di negara Belanda yang mayoritas beragama non muslim sebagai pilar pendidikan karakter Islam.

\section{Metode Penelitian}

Pada penelitian ini, penulis menggunakan pendekatan kualitatif, yang mana penulis memfokuskan kegiatan penelitian ilmiahnya dengan jalan penguraian (describing) dan pemahaman (understanding) tentang, fenomena, gejala atau kejadian sosial yang ditelaah. ${ }^{6}$ Adapun jenis pendekatan yang digunakan yaitu deskriptif, berdasarkan kenyataan yang sebenarnya. Teknik pengumpulan data melalui wawancara dan observasi. Sumber data yang didapat berupa informasi dari pihak sekolah Indonesia Den Haag (SIDH) secara online dengan menggunakan zoom meeting yang dilaksanakan pada Rabu, 19 Agustus 2020 dalam acara Internasional Virtual Fieldwork Study yang diselenggarakan oleh pihak kampus Institut Agama Islam Negeri (IAIN) Kudus.

\section{Hasil Penelitian dan Pembahasan}

Sebelum membahas lebih jauh tentang penerapan nilai-nilai keislaman dan keindonesiaan di Sekolah Indonesia Den Haag (SIDH) sebagai salah satu pilar pendidikan karakter Islam. Peneliti akan memberikan gambaran sekilas tentang Sekolah Indonesia Den Haag (SIDH) Belanda. Sekolah Indonesia Den Haag (SIDH) merupakan sekolah Indonesia yang yang dibina di bawah Kedutaan Besar Republik Indonesia (KBRI) untuk menyediakan tempat belajar bagi anak-anak Indonesia yang berada di negara Belanda dan Eropa. SIDH didirikan pada tanggal 15 Juni 1965 dan diresmikan pada tanggal 17 Agustus 1965 di Rijaksstraatweg 679, 2245 CB Wassenar, Nederlands. SIDH telah ditetapkan sebagai lembaga pendidikan formal oleh keputusan Menteri Pendidikan dan Kebudayaan RI No.048/1968, 01/06/196.

Program pembelajaran pada sekolah Indonesia Den Haag menggunakan dua program yakni, program pendidikan reguler dan program Pendidikan Jarak Jauh (PJJ). Sekolah Indonesia Den Haag (SIDH) mempunyai tiga jenjang pendidikan di antaranya yakni, Sekolah Dasar (SD), Sekolah Menengah Pertama (SMP), Sekolah

\footnotetext{
Studi Islam 0, no. 0 (2 Juni 2019): 16-29, 6 M. Djunaidi Ghony dan Fauzan Almanshur, 
Penerapan Nilai-nilai Keislaman dan Keindonesiaan Sekolah Indonesia Den Haag (SIDH) Sebagai Pilar Pendidikan

Karakter

Oleh: Khobli Arofad, Nadjma Laynufaria Almas, Ahmad Mushofihin, Veny Widiyanti Putri

Menengah Atas (SMA). SIDH memfasilitasi layanan pendidikan berstandar internasional bagi anak-anak Indonesia di Belanda dan di Eropa agar anak-anak tersebut dapat bersekolah seperti layaknya sekolah-sekolah Indonesia dan menggunakan kurikulum Indonesia. Hal ini bertujuan untuk agar anakanak tersebut mempunyai karakter dan berbudaya Indonesia yang melekat di dalam diri anak-anak Indonesia di luar negeri tersebut.

Adapun visi dan misi Sekolah Indonesia Den Haag (SIDH) yaitu:

1. Visi

"Nilai-nilai Indonesia, Standar Internasional".

2. Misi

a. Untuk memberikan layanan pendidikan yang berkualitas bagi anak-anak Indonesia di Belanda dan Eropa.

b. Untuk melayani program dan kegiatan yang memastikan ketaatan pada kehidupan beragama dan nilai-nilai Indonesia.

c. Untuk meningkatkan kompetensi profesionalisme tenaga pengajar dan non pengajar. d. Untuk menjalin kerjasama dengan sekolah asing dan internasional di Belanda dan sekitarnya.

e. Untuk menyelenggarakan publikasi budaya dan kegiatan diplomasi kepada masyarakat Belanda dan internasional di Belanda dan Eropa. ${ }^{7}$

Anak-anak di Sekolah Indonesia Den Haag (SIDH) sangat mengenggam erat nilainilai karakter di antaranya keislaman dan keindonesiaan, di mana para pendidik di Sekolah Indonesia Den Haag (SIDH) membimbing anak-anak Indonesia agar mempunyai nilai-nilai karakter tersebut. Di dalam kelas anak anak/peserta didik diajak untuk membiasakan nilai-nilai keislaman dan keindonesiaan.

Langkah yang digunakan seorang pendidik agar para anak-anak didik nilai-nilai keislaman dan keindonesiaan dapat berdaya guna, yaitu:

1. Pendidik atau guru harus mengetahui terlebih dahulu dalam memahami nilainilai keislaman dan keindonesiaan yang akan diajarkan kepada peserta didik.

2. Pendidik atau guru mentransformasikan nilai-nilai keislaman dan keindonesiaan pada peserta didik dengan penuh perasaan dan ikhlas, hal ini bisa melalui contohcontoh gurunya atau keteladanan pendidik

7 "Sekolah Indonesia Den Haag," diakses 11 Oktober 2020, http://www.sekolahindonesia.nl/. 
Penerapan Nilai-nilai Keislaman dan Keindonesiaan Sekolah Indonesia Den Haag (SIDH) Sebagai Pilar Pendidikan

Karakter

Oleh: Khobli Arofad, Nadjma Laynufaria Almas, Ahmad Mushofihin, Veny Widiyanti Putri

sehingga peserta didik dapat melihat dengan konkret alangkah baiknya nilainilai tersebut dan peserta didik dapat mengambil contoh dari gurunya tersebut.

3. Pendidik atau guru menunjang peserta didik untuk menginternalisasi nilai keislaman dan keindonesiaan dalam tingkah laku dalam kehidupan sehari-hari mereka.

4. Peserta didik yang telah merasa menguasai atau mempunyai nilai-nilai keislaman dan keindonesiaan, pendidik membantu dan mendorong untuk mewujudkan tingkah laku dalam kehidupan sehari-hari. ${ }^{8}$

\section{Penerapan Nilai-nilai Keislaman di} Sekolah Indonesia Den Haag (SIDH)

\section{Belanda}

Penerapan nilai-nilai keislaman di Sekolah Indonesia Den Haag (SIDH) adalah suatu upaya memasukkan, mengintegrasikan dan menerapkan nilai-nilai yang dapat mengembangkan, membina, dan membentuk pribadi religius. Hal ini bertujuan untuk mengarahkan peserta didik untuk menguasai dan mengimplementasikan nilai-nilai keislaman dalam kehidupan mereka sehingga dapat membentuk akhlak al karimah. Dalam mengaktualisasikan nilai-nilai keislaman tidak hanya pada skala kognitif saja, melainkan harus mengenai pada aktualisasi atau pengamalan nyata dalam kehidupan peserta didik.

Apabila seorang peserta didik terbiasa dalam mengaplikasikan nilai-nilai keislaman, diharapkan nantinya akan menjadi manusia yang mempunyai nilai religius. ${ }^{9}$ Penerapan nilai-nilai keislaman secara keseluruhan merupakan salah satu cara membentuk nilai ketakwaan dan nilai keimanan pada peserta didik terutama di negara Belanda, yang mayoritas beragama Kristen Protestan. Dalam membentuk karakter yang baik tentunya membutuhkan proses yang panjang dan membutuhkan bimbingan, keteladanan, pembiasaan serta nasehat dari guru, orang tua dan masyarakat untuk mendukung proses pembentukan karakter.

Pendidikan karakter yang diterapkan di lembaga pendidikan ini tidak hanya pada nilai keimanan atau ketakwaan saja melainkan bagaimana mereka manjadi peserta didik yang selalu terbiasa hidup disiplin, jujur, berpikir kritis, tidak sombong, berperilaku qana'ah, toleran, hemat, produktif, peduli terhadap

Karimah Siswa," Tarbiyatu Wa Ta'lim: Jurnal Pendidikan Agama Islam 1, no. 01 (31 Oktober 2019): 59-73.
8 Agus Zaenul Fitri, Pendidikan Karakter Berbasis Nilai \& Etika di Sekolah (Yogyakarta: Ar-Ruzz Media, 2014), 95.

9 Nur Hasanah Ismatullah, "Internalisasi Nilai-Nilai Keislaman Dalam Membangun Karakter Akhlakul 
Penerapan Nilai-nilai Keislaman dan Keindonesiaan Sekolah Indonesia Den Haag (SIDH) Sebagai Pilar Pendidikan

Karakter

Oleh: Khobli Arofad, Nadjma Laynufaria Almas, Ahmad Mushofihin, Veny Widiyanti Putri

lingkungan, optimis, terbiasa berperilaku ridha, dan objektif. ${ }^{10}$

Penerapan nilai-nilai keIslaman yang diterapkan di Sekolah Indonesia Den Haag (SIDH) Belanda adalah sebagai berikut:

1. Salat Jumat

Salat jumat dilaksanakan di masjid Sekolah Indonesia Den Haag (SIDH) yang dikuti seluruh peserta didik, guru, KBRI dan masyarakat Sekolah Indonesia Den Haag (SIDH) yang beragama Islam. Nilainilai keislaman yang dapat diterapkan pada salat jumat yaitu, nilai ketakwaan dan keimanan, nilai inilah yang dapat membimbing atau melatih para peserta didik menjadi sosok individu yang memiliki keimanan dan ketakwaan.

2. Membaca Al-Qur'an

Kegiatan membaca Al-Qur'an dapat membangun dan mengembangkan budaya membaca atau kegemaran membaca AlQur'an di kalangan lembaga pendidikan tersebut. Kegiatan membaca di SIDH bertujuan untuk menumbuhkan dan mengembangkan nilai-nilai keislaman di antaranya, dapat meningkatkan keimanan dan ketakwaan dalam beragama. Apabila kualitas keimanan dan ketakwaan semakin baik, maka akan membuahkan tingkah laku dan karakter peserta didik yang semakin baik. Hal ini mendorong atau membiasakan diri untuk berzikir, berdoa sebelum memulai suatu aktifitas. ${ }^{11}$

3. Menghafal Al-Qur'an

Kegiatan menghafal Al-Qur'an dapat membangun kecintaan peserta didik pada Al-Qur'an. Sekolah Indonesia Den Haag terdapat kegiatan menghafal al-Qur'an yang bertujuan untuk menumbuhkan nilainilai ketakwaan dan keimanan dalam beragama, terutama terhadap Al-Qur'an yang merupakan sumber hukum Islam pertama. Di Sekolah Indonesia Den Haag terdapat peserta didik yang sudah hafal Al-Qur'an. Menghafal juga membantu mereka untuk menjaga hafalannya dan mempraktikkan dalam keseharian hingga menjadi kebiasaan. ${ }^{12}$

Kegiatan-kegiatan Keislaman dan proses pembelajaran pendidikan agama Islam yang ada pada SIDH dapat membentuk karakter peserta didik yang insan kamil yaitu yaitu manusia yang mempunyai kemampuan

Ibtidaiyah 1, no. 2 (10 Mei 2016): 46-61, https://doi.org/10.31602/muallimuna.v1i2.385.

${ }^{12}$ Maimunatun Habibah dan Siti Wahyuni, "Literasi Agama Islam Sebagai Strategi Pembinaan Karakter Religius Siswa RA Km Al Hikmah Kediri," JCE (Journal of Childhood Education) 4, no. 1 (2020): 4661, https://doi.org/10.30736/jce.v3i2.114. 
Penerapan Nilai-nilai Keislaman dan Keindonesiaan Sekolah Indonesia Den Haag (SIDH) Sebagai Pilar Pendidikan

Karakter

Oleh: Khobli Arofad, Nadjma Laynufaria Almas, Ahmad Mushofihin, Veny Widiyanti Putri

untuk menyetarakan antara kemampuan spiritual, intelektual, dan emosional.

Pendidikan agama Islam dan pendidikan karakter merupakan komponen yang tidak dapat dipisahkan karena agama menjadi parameter dalam agama Islam tersebut, sehingga yang baik akan disangka baik oleh agama begitupun juga sebaliknya, yang buruk juga disangka buruk oleh agama. Seorang guru harus memiliki kewajiban penuh dalam mempersiapkan peserta didiknya untuk menjalani kehidupan serta mengarahkannya agar tumbuh menjadi peserta didik yang berakhlak terpuji.

Nilai-nilai keislaman merupakan suatu kebutuhan dan fitrah manusia. Dengan adanya sebuah landasan spiritual yaitu agama manusia khususnya peserta didik akan mampu dalam menjaga keseimbangan antara kejahatan dan kebaikan. Nilai-nilai keislaman sangat berpengaruh terhadap kehidupan sosial. Semua nilai-nilai yang terkandung dalam agama Islam tidak hanya mengandung pada aspek spiritualitas (teologis) akan tetapi juga mengatur dan mencakup seluruh aspek dalam kehidupan manusia. ${ }^{13}$ Pada nilai-nilai keislaman ini terbagi menjadi dua hal yang penting dalam kehidupan manusia yaitu: nilai ilahiyah, nilai yang langsung turun dari Allah SWT yang bersumber pada Al-Qur'an dan nilai insaniyah, nilai-nilai yang berkembang dan tumbuh dari peradaban manusia. ${ }^{14}$

\section{Penerapan Nilai-nilai Keindonesiaan Sekolah Indonesia Den Haag (SIDH) Belanda}

Eksistensi Sekolah Indonesia Den Haag (SIDH) sebagai sekolah Indonesia yang berada di Belanda terbukti mampu mengembangkan, merawat, dan menjaga nilai-nilai keindonesiaan sebagai salah satu wadah untuk mencetak generasi atau karakter keindonesiaan yang diharapkan bangsa Indonesia dan tetap eksis walaupun di luar negeri yaitu Belanda. Nilai-nilai inilah yang menjadi acuan atau penentu dalam menentukan perilaku para peserta didik SIDH. Nilai-nilai karakter adalah nilai-nilai yang mendasari perilaku-perilaku manusia yang bersumber pada norma agama, kebudayaan, adat istiadat, hukum, dan, estetika. Apabila dikaitkan dengan pendidikan, pendidikan karakter, pelaksanaan nilai-nilai perilaku atau kepribadian yang meliputi, kemauan, kesadaran, pengetahuan dan perbuatan untuk memanifestasikan nilai-
13 Nurul Jeumpa, "Nilai-Nilai Agama Islam," Pedagogik: Jurnal Ilmiah Pendidikan Dan Pembelajaran Fakultas Tarbiyah Universitas Muhammadiyah Aceh 4, no. 2 (8 Mei 2018): 101-12.
14 Lilik Nur Kholidah, "Pola Integrasi Nilai-nilai Keislaman dalam Pembelajaran Pendidikan Agama Islam pada Lembaga Pendidikan," At-Ta'dib 10, no. 2 (8 Desember 2015), https://doi.org/10.21111/attadib.v10i2.459. 
Penerapan Nilai-nilai Keislaman dan Keindonesiaan Sekolah Indonesia Den Haag (SIDH) Sebagai Pilar Pendidikan

Karakter

Oleh: Khobli Arofad, Nadjma Laynufaria Almas, Ahmad Mushofihin, Veny Widiyanti Putri

nilai tersebut terhadap Tuhan Yang Maha Esa, orang lain, lingkungan, kebangsaan dan dirinya sendiri. Pendidikan di SIDH menjadikan peserta didik memiliki karakter sentral yaitu, manusia yang beragama, manusia sebagai warga bangsa, manusia sosial, dan manusia sebagai pribadi. ${ }^{15}$

Berdasarkan karakter sentral tersebut SIDH mengembangkan suatu pembiasaan berasumsi dan bertindak yang memfokuskan pada delapan belas nilai-nilai kehidupan, hal ini bertujuan untuk membentuk karakter keindonesiaan peserta didik walaupun sekolahnya berada di luar negeri yaitu Belanda dan Eropa. Pada SIDH inilah para guru mendidik para peserta didiknya agar selalu tertanam nilai-nilai keindonesiaan ke dalam diri peserta didik agar tidak lupa terhadap bangsa Indonesia. Penanaman nilainilai karakter keindonesiaan dapat dilaksanakan dengan kegiatan ekstrakurikuler yang diselenggarakan oleh SIDH.

Karakter keindonesiaan merupakan karakter manusia Indonesia yang membedakan dengan manusia dari bangsa lain sebagai suatu manifestasi terhadap esksistensi diri dan citra diri bangsa Indonesia. Adapun landasan karakter

15 Nana Najmina, "Pendidikan Multikultural Dalam Membentuk Karakter Bangsa Indonesia," JUPIIS: JURNAL PENDIDIKAN ILMU-ILMU SOSIAL 10, no. 1 (29 Juni 2018): 52-56, https://doi.org/10.24114/jupiis.v10i1.8389. keindonesiaan adalah semangat kebangsaan dan cinta tanah air. Hal ini menjadi penanda dari berbagai keberagaman bangsa di dunia. Dengan ini, SIDH menerapkan nilai-nilai karakter keindonesiaan sebagai wujud semangat kebangsaan dan cinta tanah air dan sebagai pembeda dari bangsa-bangsa yang lain.

Esensi pendidikan karakter di Indonesia terdapat sembilan pilar karakter yakni, (1) cinta kepada Allah dan semesta beserta isinya, (2) tanggung jawab, disiplin dan mandiri, (3) jujur, (4) hormat dan santun, (5) kasih sayang, peduli, dan kerjasama, (6) percaya diri, kreatif, kerja keras, dan pantang menyerah, (7) keadilan dan kepemimpinan, (8) baik hati dan rendah hati, dan (9) toleransi, cinta damai dan persatuan. Sembilan pilar di atas memfokuskan terhadap pembentukan dan pembinaan karakter baik yang bersandar pada nilai-nilai agama, pancasila, budaya dan tujuan pendidikan nasional. ${ }^{16}$

Dari keempat sumber landasan utama tersebut maka lahirlah delapan belas nilai karakter keindonesiaan yang merupakan sebuah rujukan pendidikan. Adapun delapan belas nilai karakter tersebut meliputi nilai religius, jujur, toleransi, disiplin, bekerja

\footnotetext{
16 Sofyan Mustoip, Muhammad Japar, dan Zulela MS, Implementasi Pendidikan Karakter (Surabaya: Jakad Publishing, 2018), 60-61.
} 
Penerapan Nilai-nilai Keislaman dan Keindonesiaan Sekolah Indonesia Den Haag (SIDH) Sebagai Pilar Pendidikan

Karakter

Oleh: Khobli Arofad, Nadjma Laynufaria Almas, Ahmad Mushofihin, Veny Widiyanti Putri

keras, kreatif, mandiri, demokratis, rasa ingin tahu, semangat kebangsaan, cinta tanah air, menghargai prestasi, komunikatif, cinta damai, gemar membaca, peduli lingkungan, peduli sosial, dan bertanggung jawab.

Pada Peraturan Menteri Pendidikan dan Kebudayaan RI Nomor 20 Tahun 2018 tentang "Penguatan Pendidikan Karakter pada Satuan Pendidikan Formal" pada pasal 2 ayat 2 yang berbunyi: "Nilai sebagaimana dimaksud pada ayat (1) merupakan perwujudan dari 5 (lima) nilai utama yang saling berkaitan yaitu, religiusitas, nasionalisme, kemandirian, gotong royong, dan integritas yang terintegrasi dalam kurikulum". ${ }^{17}$ Pasal tersebut menjelaskan bahwa nilai-nilai karakter keindonesiaan merupakan manifestasi dari 4 (empat) nilai utama yang telah disebutkan di atas.

Adapun penerapan nilai-nilai keindonesiaan di SIDH dalam memperkuat nilai-nilai karakter keindonesiaan sebagai warga negara Indonesia yang menjadi ciri khas bangsa Indonesia adalah sebagai berikut:

1. Religius : mengucapkan salam, berdoa sebelum memulai belajar dan sesudah belajar, menghormati pelaksanaan ibadah dari agama lain, membaca Al-Qur'an, menghafal Al-Qur'an, merayakan hari besar keagamaan dan berakhlak mulia

2. Jujur: tidak melakukan kebohongan antar sesama dan guru

3. Toleransi : memahami dan menghargai keyakinan atau kebiasaan temannya dan tidak melakukan tindakan bullying.

4. Disiplin : hadir tepat waktu, menjalankan tata tertib sekolah, tidak melanggar peraturan-peraturan sekolah, dan lainnya.

5. Kerja keras: Adanya prestasi-prestasi baik secara nasional maupun internasional, berkompetisi secara fair dan berusaha semaksimal mungkin dalam menyelesaikan atau tugas secara optimal.

6. Kreatif : adanya ide dan karya-karya ciptaan siswa yang bermanfaat dan membanggakan sekolah.

7. Mandiri : adanya berkerja secara mandiri/individu baik di dalam sekolah maupun di luar sekolah dan tugas-tugas yang diberikan kepada peserta didik dan tidak ketergantungan pada orang lain.

8. Demokratis : adanya peserta didik yang tidak memaksakan kehendak antar sesama, bermusyawarah mufakat, dan lainnya.

9. Rasa ingin tahu: menyelidiki materimateri pembelajaran, mengajukan

17 Kementerian Pendidikan dan Kebudayaan, Penguatan Pendidikan Karakter pada Satuan "Peraturan Menteri Pendidikan dan Kebudayaan Pendidikan Formal," diakses 27 Oktober 2020, Republik Indonesia Nomor 20 tahun 2018 tentang https://jdih.kemdikbud.go.id/. 
Penerapan Nilai-nilai Keislaman dan Keindonesiaan Sekolah Indonesia Den Haag (SIDH) Sebagai Pilar Pendidikan

Karakter

Oleh: Khobli Arofad, Nadjma Laynufaria Almas, Ahmad Mushofihin, Veny Widiyanti Putri

pertanyaan terhadap suatu objek atau peristiwa yang belum diketahuinya

10. Semangat kebangsaan : adanya upacara sekolah, memperingati hari-hari besar nasional, meneladani para pahlawan, kegiatan kebudayaan dan lainnya.

11. Cinta tanah air: melestarikan atau mempromosikan seni dan budaya bangsa Indonesia, bangga dengan bangsa Indonesia walaupun di negara Belanda, menanamkan rasa nasionalisme dan rasa persatuan dan kesatuan bangsa Indonesia, dan lainnya.

12. Menghargai prestasi : adanya semangat dalam mengembangkan prestasi-prestasi dengan menyontoh prestasi dari generasi sebelumnya dan menghargai teman yang berprestasi.

13. Bersahabat/Komunikatif : bergaul dengan teman, saling bekerja sama, dan tidak pernah membedakan satu sama lain.

14. Cinta damai: memelihara perdamaian baik dengan orang Belanda, sesama teman dan guru, menghindari atau menyelesaikan masalah dengan baik.

15. Gemar membaca: membaca buku untuk menambah wawasan.

16. Peduli lingkungan: adanya sikap peduli terhadap segala makhluk ciptaan Allah, baik manusia, hewan dan tanaman.
17. Peduli sosial: membantu teman yang kesusahan atau yang baru terkena musibah.

18. Tanggung jawab: rajin melaksanakan piket sesuai jadwal, mengerjakan tugas dari guru, bertanggung jawab atas segala perbuatan yang dilakukannya.

Esensi nilai-nilai keindonesiaan merupakan bagian terpenting dalam pengembangan dan memperkuat pendidikan karakter bangsa. Pada dasarnya, pendidikan karakter keindonesiaan tidak hanya berkaitan dengan internalisasi dan transformasi nilainilai keindonesiaan kepada peserta didik saja, namun pendidikan karakter keindonesiaan merupakan suatu proses upaya mewujudkan lingkungan yang kontributif untuk memperkuat dan mengembangkan nilai-nilai kehidupan baik secara individu, masyarakat, dan bangsa. ${ }^{18}$

Pembentukan karakter keindonesiaan di SIDH berfungsi untuk menumbuhkan atau menunjang kesadaran diri para peserta didik. Pada dasarnya kesadaran diri adalah pendalaman diri sebagai hamba Tuhan Yang Maha Esa, sebagai warga negara, sebagai bagian dari lingkungan, mensyukuri atas nikmat yang telah diberikan, menyadari atas segala kelebihan dan kekurangan yang

18 Hartono, "Pendidikan Karater dalam Kurikulum Sejarah dan Nilai Tradisional 19, no. 2 (2014): 2592013," Jnana Budaya: Media Informasi dan Publikasi 68. 
Penerapan Nilai-nilai Keislaman dan Keindonesiaan Sekolah Indonesia Den Haag (SIDH) Sebagai Pilar Pendidikan

Karakter

Oleh: Khobli Arofad, Nadjma Laynufaria Almas, Ahmad Mushofihin, Veny Widiyanti Putri

dimilikinya, serta menjadi pribadi yang bermanfaat bagi diri sendiri atau orang lain.

Penerapan nilai-nilai keindonesiaan yang memfokuskan baik dan buruk dapat membentuk karakter-karakter yang kuat. Apabila dari kecil anak sudah dibiasakan untuk berperilaku atau berkarakter positif maka anak akan tumbuh dengan menjadi pribadi atau karakter yang kuat dan positif, begitupun sebaliknya.

SIDH sangat memperhatikan karakterkarakter para peserta didiknya di negara Belanda, terutama dalam bersikap di negara Belanda yang kebanyakan sikap dan perilaku cukup berbeda dengan bangsa Indonesia. Penanaman nilai karakter keindonesiaan menumbuhkan rasa cinta dan bangga terhadap bangsa Indonesia, dengan mengenalkan berbagai budaya-budaya Indonesia termasuk salah satu sikap untuk menumbuhkan karakter-karakter keindonesiaan pada peserta didik di SIDH.

Prinsip yang digunakan pada penguatan pendidikan karakter tercantum pada Peraturan Menteri Pendidikan dan Kebudayaan RI Nomor 20 Tahun 2018 tentang "Penguatan Pendidikan Karakter pada Satuan Pendidikan Formal" pada pasal 3 yang berbunyi: a. Berorientasi pada berkembangnya potensi peserta didik secara menyeluruh dan terpadu

b. Keteladanan dalam penerapan pendidikan karakter pada masing-masing lingkungan pendidikan.

c. Berlangsung melalui pembiasaan dan sepanjang waktu dalam kehidupan seharihari. ${ }^{19}$

SIDH Belanda sangat memegang prinsip-prinsip di atas dalam memperkuat karakter-karakter para peserta didiknya. Penguatan karakter di SIDH sangat diperhatikan penuh agar peserta didik mampu mengimplementasikan dalam kehidupan sehari-harinya. Tentunya agar nilai-nilai karakter keindonesiaan selalu melekat dalam diri peserta didik, harus melalui pembiasaanpembiasaaan sepanjang waktu.

Ada empat hal yang dapat mempengaruhi belajar peserta didik sebagai perwujudan pembinaan karakter peserta didik di antaranya, lingkungan sekolah, belajar mengajar, ekstrakurikuler, dan interaksi orang tua dan masyarakat. Hal ini berguna untuk menumbuhkembangkan nilai-nilai karakter khususnya nilai karakter keindonesiaan para peserta didik melalui segala proses penggalian dan pembinaan yang cermat sebagai bagian dari pencapaian tujuan pendidikan nasional.

19 Kebudayaan, "Peraturan Menteri Pendidikan dan tentang Penguatan Pendidikan Karakter pada Satuan Kebudayaan Republik Indonesia Nomor 20 tahun 2018 
Penerapan Nilai-nilai Keislaman dan Keindonesiaan Sekolah Indonesia Den Haag (SIDH) Sebagai Pilar Pendidikan

Karakter

Oleh: Khobli Arofad, Nadjma Laynufaria Almas, Ahmad Mushofihin, Veny Widiyanti Putri

\section{Kesimpulan}

Berdasarkan pemaparan di atas, dapat disimpulkan bahwa penerapan nilai-nilai keislaman di SIDH berjalan dengan baik walaupun berada di luar negeri, yaitu Belanda dan Eropa. Penerapan nilai-nilai keislaman membentuk peserta didik yang insan kamil, begitupun juga nilai-nilai keindonesiaan juga dapat meningkatkan peserta didik yang berkarakter. Nilai-nilai keislaman dan keindonesiaan saling melengkapi satu sama lain. Nilai-nilai tersebut sebagai pilar pendidikan karakter Islam sangat berarti dalam pembentukan akhlak atau karakter peserta didik di negara Belanda maupun di Eropa. Hal ini mendorong para pihak SIDH mengutamakan pendidikan karakter sebagai pembentukan akhlak atau karakter yang sesuai dengan nilai-nilai keislaman dan nilainilai keindonesiaan.

\section{Daftar Pustaka}

Fautanu, Idzan. "Reaktualisasi Nilai-Nilai Keislaman Untuk Membangun Karakter Bangsa." Al-Risalah 11, no. 02 (1 Desember 2018): 1-13. https://doi.org/10.30631/alrisalah.v11i02.465.

Fitri, Agus Zaenul. Pendidikan Karakter Berbasis Nilai \& Etika di Sekolah. Yogyakarta: Ar-Ruzz Media, 2014.

Ghony, M. Djunaidi, dan Fauzan Almanshur. Metodologi Penelitian Kualitatif. Yogyakarta: Ar-Ruzz Media, 2012.

Habibah, Maimunatun, dan Siti Wahyuni. "Literasi Agama Islam Sebagai
Strategi Pembinaan Karakter Religius Siswa RA Km Al Hikmah Kediri." JCE (Journal of Childhood Education) 4, no. 1 (2020): 46-61. https://doi.org/10.30736/jce.v3i2.114.

Hartono. "Pendidikan Karater dalam Kurikulum 2013." Jnana Budaya: Media Informasi dan Publikasi Sejarah dan Nilai Tradisional 19, no. 2 (2014): 259-68.

Ismatullah, Nur Hasanah. "Internalisasi NilaiNilai Keislaman Dalam Membangun Karakter Akhlakul Karimah Siswa." Tarbiyatu Wa Ta'lim: Jurnal Pendidikan Agama Islam 1, no. 01 (31 Oktober 2019): 59-73.

Jeumpa, Nurul. "Nilai-Nilai Agama Islam." Pedagogik: Jurnal Ilmiah Pendidikan Dan Pembelajaran Fakultas Tarbiyah Universitas Muhammadiyah Aceh 4, no. 2 (8 Mei 2018): 101-12.

Kebudayaan, Kementerian Pendidikan dan. "Peraturan Menteri Pendidikan dan Kebudayaan Republik Indonesia Nomor 20 tahun 2018 tentang Penguatan Pendidikan Karakter pada Satuan Pendidikan Formal." Diakses $27 \quad$ Oktober 2020. https://jdih.kemdikbud.go.id/.

Kholidah, Lilik Nur. "Pola Integrasi Nilainilai Keislaman dalam Pembelajaran Pendidikan Agama Islam pada Lembaga Pendidikan." At-Ta'dib 10, no. 2 (8 Desember 2015). https://doi.org/10.21111/attadib.v10i2.459.

Mulia, Musda, dan Ira D. Aini. Karakter Manusia Indonesia: Butir-butir Pendidikan Karakter untuk Generasi Muda. Bandung: Nuansa Cendekia, 2013.

Mustoip, Sofyan, Muhammad Japar, dan Zulela MS. Implementasi Pendidikan Karakter. Surabaya: Jakad Publishing, 2018. 
Penerapan Nilai-nilai Keislaman dan Keindonesiaan Sekolah Indonesia Den Haag (SIDH) Sebagai Pilar Pendidikan Karakter

Oleh: Khobli Arofad, Nadjma Laynufaria Almas, Ahmad Mushofihin, Veny Widiyanti Putri

Najmina, Nana. "Pendidikan Multikultural Dalam Membentuk Karakter Bangsa Indonesia." JUPIIS: JURNAL PENDIDIKAN ILMU-ILMU SOSIAL 10, no. 1 (29 Juni 2018): 52-56. https://doi.org/10.24114/jupiis.v10i1. 8389.

Permana, Erwin Putera, Frans Aditia Wiguna, dan Novita Dewi Rosalia. "Pengembangan Permainan Berlandaskan Nilai Karakter Keindonesiaan pada Siswa Sekolah Dasar." PINUS: Jurnal Penelitian Inovasi Pembelajaran 5, no. 1 (12 November 2019): 99-107. https://doi.org/10.29407/pn.v5i1.1385 7.

Rafsanjani, Toni Ardi, dan Muhammad Abdur Razaq. "Internalisasi Nilai-Nilai Keislaman Terhadap Perkembangan Anak Di Sekolah Dasar Muhammadiyah Kriyan Jepara." Profetika: Jurnal Studi Islam 0, no. 0 (2 Juni 2019): 16-29. https://doi.org/10.23917/profetika.v20 i1.8945.

"Sekolah Indonesia Den Haag." Diakses 11 Oktober 2020 . http://www.sekolahindonesia.nl/.

Situmorang, Asril Azis. "Komunikasi keluarga dalam penerapan nilai-nilai keislaman di Kelurahan Simatorkis Sisoma Kecamatan Angkola Barat." Undergraduate, IAIN Padangsidimpuan, 2012. http://etd.iainpadangsidimpuan.ac.id/5678/.

Simkeu Kemendikbud. "UU No. 20 Tahun 2003 Tentang Sistem Pendidikan Nasional." Diakses 11 Desember 2020.

http://simkeu.kemdikbud.go.id/index. php/peraturan $1 / 8$-uu-undangundang/12-uu-no-20-tahun-2003tentang-sistem-pendidikan-nasional.
Zulkifli, Muhammad. "Pembentukan Karakter Gemar Membaca Alquran." Muallimuna: Jurnal Madrasah Ibtidaiyah 1, no. 2 (10 Mei 2016): 4661. https://doi.org/10.31602/muallimuna. v1i2.385. 